\title{
UN LENGUAJE QUE NO DICE NADA (Y QUE NO SE CALLA JAMÁS). LA INFLUENCIA DE NIETZSCHE EN LA TEORÍA LITERARIA DE MICHEL FOUCAULT
}

\author{
A language that says nothing (and is never silent).
} Nietzsche's influence on Michel Foucault's literary theory

\author{
Antonio Castilla Cerezo \\ Universidad de Barcelona
}

\begin{abstract}
Resumen: Para mostrar las principales influencias del pensamiento de Nietzsche sobre la teoría literaria de Michel Foucault, este artículo revisa las siguientes cuatro inversiones: en primer lugar, la del modelo comunicativo de Lasswell; segundo, la del platonismo; tercero, la del hegelianismo; cuarto y último, la de schopenhauerianismo, (esta última, tanto en lo que respecta a la metafísica como a la estética). Nos ha parecido que, por contraste con estos referentes, no solo la influencia de Nietzsche sobre Foucault, sino también la posición de este último en relación al fenómeno literario, se clarifican notablemente.
\end{abstract}

Palabras clave: Nietzsche - Foucault - filosofía - literatura

ABSTRACT: To show the main influences of Nietzsche's thought on Michel Foucault's literary theory, this article reviews the following four inversions: first, that of Lasswell's communicative model; second, that of platonism; third, that of hegelianism; fourth and last, schopenhauerianism, (the latter, both in terms of metaphysics and aesthetics). It seemed to us that, in contrast to these references, not only Nietzsche's influence on Foucault, but also Nietzsche's position on the literary phenomenon, are remarkably clarified.

Keywords: Nietzsche - Foucault - philosophy - literature 


\section{LA INVERSIÓN DEL MODELO DE LASSWELL}

En una entrevista con Raymond Bellour publicada en 1966 en Les Lettres françaises, Michel Foucault puso tres ejemplos de un fenómeno que le parecía que caracterizaba a su época, y que no era otro que la incompatibilidad entre «el orden de los signos»y «el orden del hombre». El tercero y último de estos tres ejemplos era la literatura, que a juicio de este pensador francés dejó en el siglo XIX de pertenecer al orden del discurso (o sea, del lenguaje razonable y razonado, que atiende a unas prescripciones que, a su vez, intenta inculcar en el lector) para devenir «la manifestación del lenguaje en su espesor» ${ }^{1}$. De este acontecimiento - que desde mediados del siglo XX se tradujo en el ámbito literario, de nuevo según Foucault, en una escisión entre los «humanistas blandos» y el formalismo puro (de, por ejemplo, la «nueva novela» francesa) - Nietzsche habría sido consciente antes que nadie, y de ahí que este autor «para nosotros (...) haya adquirido un valor profético» ${ }^{2}$. Así, la lección que el autor de Así habló Zaratustra nos habría dirigido, y que la literatura no habría cesado de hacer resonar desde entonces, no es otra que la siguiente: allí donde hay signo, no puede ser la centralidad de lo humano lo que dé razón de nuestro uso del lenguaje.

Foucault observa en esta misma entrevista que lo que le resulta ingenuo en todos los análisis sobre los signos es que siempre parecen suponer la existencia de estos últimos, bien como depositados (por una instancia divina o trascendente) en el mundo, bien en tanto que constituidos por el ser humano (es decir, por una instancia inmanente). Lo que respecto a este punto el siglo XIX (y, muy en particular, Nietzsche) habría señalado es, así, que los signos tienen su propia entidad, de modo que no son un simple medio para la manifestación de Dios en el mundo o para la expresión de una interioridad humana. En otras palabras, podrá haber una conciencia propiamente moderna de los signos solo en la medida en que sea posible romper con la concepción puramente instrumental los mismos. Es así porque, si en la modernidad el modus es objeto de una atención autónoma respecto a la substantia y no ya un simple medio que tendría sentido solo por su supeditación a ésta, entonces la comprensión moderna de los signos no podrá sostenerse ni sobre el teísmo ni sobre el humanismo, sino únicamente sobre el propio ser del signo, siendo justamente esta peculiar situación lo que la literatura moderna (o, lo que es igual para Foucault, la literatura sin más) habría logrado manifestar.

Avanzando todavía un paso más en este sentido, añadiremos que la concepción premoderna de los signos, en la medida en que entiende a estos últimos como instrumentos al servicio de un emisor que pretende hacer llegar

1 M. Foucault, Dits et écrits I, París: Gallimard, 2001, p. 530.

2 Ibid., p. 531. 
un mensaje a un receptor, comporta una teoría de la comunicación asimilable en términos generales a la explicitada en el modelo de Lasswell - según el cual, como es sabido, en el análisis de todo acto comunicativo hay que determinar, siempre en este mismo orden, las siguientes cuestiones:

\author{
¿Quién \\ dice qué \\ en qué canal \\ a quién \\ y con qué efecto? ${ }^{3}$
}

Invirtiendo este modelo, para la concepción del signo (y, por consiguiente, de la literatura) que Foucault suscribió durante la década de los sesenta del siglo pasado lo más relevante no es el emisor (y de ahí las «muertes» de Dios - en Nietzsche -, del Hombre - en Foucault -, del autor - en Barthes y, de nuevo, en Foucault -, etc.) y su(s) propósito(s), ni tampoco el mensaje que, después de haber sido transmitido, llevaría a este emisor a callar (de donde se sigue, a su vez, el que para Foucault la literatura se haya definido desde Nietzsche - que pregunta hasta el extremo quién habla - y Mallarmée - que responde que quien habla es la palabra misma - como un «lenguaje que no dice nada, que no se calla jamás» ${ }^{4}$ ), así como tampoco la elección de un canal que sería tanto más apto cuanto más libre de interferencias (motivo por el que Foucault asumió que el uso literario del lenguaje es un «murmullo continuo ${ }^{5}$, en sintonía con el pasaje en el que Maurice Blanchot declaró que la literatura no es sino «el murmullo gigantesco sobre el cual, abriéndose, el lenguaje se hace imagen ${ }^{6}$ ), por solo hablar de los tres primeros elementos del mencionado modelo.

\title{
II. LA INVERSIÓN DEL PLATONISMO
}

Esta primera inversión nos parece, con todo, únicamente la epidermis de un proyecto mucho más amplio y que afecta al desarrollo del conjunto de la empresa que Nietzsche reconoció como propia, a saber: aquella que tiene como lema genérico «la inversión del platonismo». El paso inmediatamente sucesivo de nuestra indagación consistirá, pues, en intentar determinar el

3 H. D. Lasswell, "Estructura y función de la comunicación en la sociedad", en M. De Moragas (ed.), Sociología de la comunicación de masas, tomo II, Barcelona: Gustavo Gili, 1985, p. 51.

4 M. Foucault, Las palabras y las cosas, trad. de E. C. Frost, Buenos Aires: Siglo XXI, 2003, p. 298.

5 M. Foucault, De lenguaje y literatura, trad. de I. Herrera Baquero, Barcelona: Paidós, 1996, p. 70 .

6 M. Blanchot, El espacio literario, trad. de J. Jinkins y V. Palant, Buenos Aires: Paidós, 1992, p. 102 
vínculo que esa nueva inversión mantiene con algunos de los problemas literarios que interesaron decisivamente a Foucault.

En este punto asumiremos, para empezar, que el platonismo es solidario de una concepción de la filosofía según la cual ésta no es sino la búsqueda del saber absoluto y completo (es decir, de la sophia) por métodos racionales. Dicho saber, que es lo que finalmente serviría en cada caso para discernir entre las verdaderas y las falsas apariencias, es concebido como un conocimiento de lo eterno e inmutable, o sea, del modelo o de la «idea», que a su vez queda caracterizada en esta concepción como el criterio mediante el cual las «buenas» apariencias (o, también, las copias o los «iconos») son separadas de las «malas» (esto es, de los simulacros o «fantasmas»). Como resultado de ello, invertir el platonismo no consistirá tanto en cuestionar la diferencia entre el modelo y la copia como en impugnar la separación entre las copias y los simulacros $-\mathrm{y}$, consiguientemente, en devolver a estos últimos a la superficie, restituyéndoles de ese modo no solo su poder de fascinación, sino también su peligro.

Foucault dedicó al estudio de este peligro -que juzgó inherente a toda literatura moderna - un artículo titulado «La prosa de Acteón», centrado en la obra de Pierre Klossowski. Este escrito parte de la idea de que el cristianismo (ese «platonismo para el pueblo»), pese a condenar a la gnosis, conservó su pensamiento binario (a la vez cognoscitivo y moral, ya que la «verdadera» imagen es para el cristianismo a la vez la «buena», mientras que la «falsa» es la «mala»), por lo que extraer las consecuencias de la muerte de Dios (o sea, invertir el platonismo) no podrá consistir en la simple sustitución del Bien por el Mal como objeto de adoración, ya que tal cosa supondría la conservación de un dualismo moral (y cognoscitivo) que, en última instancia, proviene de Platón. En lugar de eso, liberarse de toda lógica dualista comportará la entrega a los peligrosos juegos, llenos de vueltas y revueltas, de la extrema similitud - o, si se quiere, a las imprevisibles mutaciones de «Dios que se parece tanto a Satán que imita tan bien a Dios» $\rangle^{7}$-, riesgo que se encuentra simbolizado, en la obra de Klossowski, por el mito de Diana y Acteón, donde la diosa es el símbolo del simulacro en su ambigüedad esencial, en tanto que la prosa de Acteón es ese lenguaje impuro (por dualista) que, al intentar traducir el enigma inherente a la diosa a sus propios términos, no puede sino presentarse como una palabra profana o, lo que es igual, transgresora. Por todo ello Foucault considera, en primer lugar, que la recuperación del espacio del simulacro, en el que la inversión del platonismo se concretaría en un lenguaje, constituye el lugar propiamente contemporáneo de la literatura; y, segundo, que la obra

7 M. Foucault, Entre filosofia y literatura. Obras esenciales, Volumen I, trad. de M. Morey, Barcelona: Paidós, 2003, p. 202. 
de Klossowski, que es una de las que lo descubren, es uno de esos rincones privilegiados en los que nos es dado constatar que el ser de la literatura no concierne ni al Hombre ni a Dios, sino solo «a este espacio del doble» ${ }^{8}$.

\section{LA INVERSIÓN DEL HEGELIANISMO}

Nos parece que para extraer las implicaciones de esa inversión del platonismo que, en función de lo que acabamos de exponer, tendría lugar en la literatura debemos partir de la siguiente consideración: dado que (según argumenta Platón en el Fedón) el cuerpo obstaculiza - porque necesita alimento, enferma en ocasiones e, incluso, nos colma «de amores y deseos, de miedos y de fantasmas de todo tipo, y de una enorme trivialidad» $(66 \mathrm{~b})^{9}-$ la reflexión que lleva al alma a la adquisición de esa verdad universal e indudable a la que hemos dado en llamar sophia, esta última solo podrá ser alcanzada por el alma que, tras esforzarse en vida por apegarse lo menos posible al cuerpo, se separe casi por completo pura de éste tras la muerte. Así, si Platón termina por admitir (en Fedón 80e y ss., por ejemplo) la existencia de una realidad trascendente en la que el alma continuaría existiendo tras separarse del cuerpo es solo por cuanto, de lo contrario, el anhelo propiamente filosófico (esto es, la consecución de la sophia) no sería realizable; y, entonces, al perseverar en la búsqueda de ese saber certero y exhaustivo pese a tener conciencia de la imposibilidad de su consecución, el filósofo actuaría como un loco - si es que el loco es aquel sujeto que, como observó Kojève en una de sus lecciones sobre la Fenomenología del espíritu de Hegel, «pretende o quiere ser lo que no puede y (todavía más grave), lo que sabe que es imposible» ${ }^{10}$. Pero, en tal caso, habrá que pensar que lo que en Platón comienza como un ejercicio racional termina por derivar en la asunción de un orden trascendente que el filósofo solo entrevería por recurso a la razón y que, en rigor, trasciende por principio a dicho uso, ya que es lo que en última instancia le confiere sentido. Es así como cabe identificar en Platón la convivencia de dos líneas de pensamiento que a lo largo de la historia de Occidente tendieron a separarse de manera cada vez más nítida, a saber: por una parte, la pretensión de obtener un saber absolutamente cierto a través de medios puramente racionales (entendiendo que éstos no remiten en modo alguno a una trascendencia del tipo que sea) y, por otra, la de alcanzar ese mismo saber, no ya mediante la razón, sino como resultado de la actividad propia del asceta (es decir, de la contemplación). El primero de estos dos caminos desemboca en Hegel, en tanto que el segundo

8 Ibid., p. 203.

9 Platón, Diálogos III, trad. de C. García Gual, Madrid: Gredos, 1988, p. 44.

10 A. Kojève, La concepción de la antropología y del ateísmo en Hegel, trad. de J. J. Sebreli y A. Llanos, Buenos Aires: Leviatán, 2007, p. 23. 
nos conduce hasta Schopenhauer - es decir, a dos autores que presuponen, con Platón, que la verdad puede ser completamente desvelada, difiriendo tan solo en el medio que cada uno de ellos considera apropiado para dicho fin.

No resulta extraño, en virtud de lo que acabamos de decir, que la inversión del platonismo llegue a plantearse como tarea explícita en Nietzsche, esto es, justo después de que las dos líneas de pensamiento que en Platón permanecieron cruzadas alcanzasen sus respectivas culminaciones por separado (con Hegel y Schopenhauer, como hemos observado). Pero que Nietzsche llegase a plantear esta inversión no significa que lograse consumarla, ya que para ello habría sido preciso prolongarla doblemente, o sea, tanto en la inversión del hegelianismo como en la del schopenhauerianismo - siendo estas dos nuevas inversiones las que nos parece posible identificar en algunos de los escritos de Michel Foucault sobre literatura. Pensamos, pues, que si Nietzsche es el faro que guía a este respecto las investigaciones de Foucault es porque advirtió lo que resulta esencial en este punto, a saber: la necesidad de entender la filosofía no ya como el esfuerzo por desvelar absolutamente una verdad preexistente, sino como una experimentación en la que la «verdad» es a la vez descubierta y producida, conocida y poetizada - o, si se quiere, desvelada y revelada (en el sentido de «vuelta a velar», ahora por medio de una nueva apariencia que resulta de la actividad misma del filósofo-artista). Aún de otro modo: si la finalidad de la especulación filosófica no es presentarnos una verdad despojada de toda mentira, es porque su propósito último consiste en darnos que pensar (y, a través de ello, que percibir, que sentir y, en general, que experimentar). Esta nueva concepción de la verdad (y, en consecuencia, del sentido de la actividad del filósofo), identificable tanto en los escritos póstumos de Nietzsche (así, por ejemplo, en el fragmento en el que éste declara que el filósofo «conoce poetizando, y poetiza conociendo» ${ }^{11}$ ) como en sus textos de juventud (Sobre verdad y mentira en sentido extramoral) o en sus obras de madurez (el prólogo y la sección primera de Más allá del bien y del mal, por citar de nuevo solo un caso), ¿no es la propia de los «filósofos del futuro» a los que este pensador creyó adivinar en el horizonte? Y, si así fuera, ¿qué relación guardaría la liberación de nuestras potencias (de pensamiento, de percepción, de sentimiento, etc.) con la preocupación de estos «nuevos filósofos» (de los que acaso Foucault y, antes que él, Klossowski y Blanchot constituyen ejemplos notorios) por los problemas literarios?

Para intentar responder a estas últimas dos cuestiones nos parece preciso no solo retener algo de lo que ya hemos dicho (a saber: que la inversión del platonismo que Nietzsche se propuso resulta indisociable de una nueva

11 P I 20B Verano de 1872- Comienzo de 1873, 19 [62], en F. Nietzsche, Fragmentos póstumos, vol. 1: 1869-1874, trad. de L. E. de Santiago Guervós, Madrid: Tecnos, 2007, p. 338. 
caracterización de la verdad y de la actividad filosófica), sino también advertir, en primer lugar, que fue casi con toda seguridad Schopenhauer quien (como educador) hizo sentir a Nietzsche la necesidad de mostrar que esa trayectoria que, iniciándose en Platón, culmina en Hegel (esto es, nada menos que el tramo mayor de la historia de la metafísica), no es sino la historia de un largo error; y, segundo, que el autor de El mundo como voluntad y representación no hizo (como filósofo) esto último sino presuponiendo que podía accederse a la verdad absoluta (o sea, a aquello por comparación con lo cual «el resto no es sino literatura») por vías ya no estrictamente racionales, sino de carácter ascético y contemplativo, de modo que finalmente no cuestionó la concepción de la verdad más o menos explícitamente asumida por los principales representantes de la tradición metafísica. El joven Nietzsche se habría hecho eco de esta superioridad de lo místico sobre lo racional al conceder a lo dionisíaco una prioridad metafísica sobre lo apolíneo en El nacimiento de la tragedia, pero no tardaría demasiado en desprenderse de esta herencia schopenhaueriana - y ello, al tiempo en que arraigaba en él esa nueva concepción de la verdad a la que ya nos hemos referido, y según la cual nuestras verdades no son sino manifestaciones peculiares de la ficción, y no aquello que subsistiría una vez suprimido todo lo ilusorio.

Pensamos que esta ruptura de Nietzsche con el presunto saber absoluto del místico tiene lugar, paradójicamente, en unos términos que se encuentran prefigurados en la obra de Hegel. En efecto, para este último son únicamente posibles (como de nuevo ha señalado Kojève) las siguientes tres actitudes existenciales básicas: primero, negar el ideal (platónico-hegeliano) del sabio esto es, posicionarse contra toda filosofía y, más aún, privar de sentido a todo discurso humano (lo que, en su forma más radical, «culmina en el silencio absoluto» ${ }^{12}$ ); segundo, aceptar dicho ideal, pero negando que el ser humano pueda realizarlo en «esta» vida (como asumía, según vimos, Platón en un punto avanzado del Fedón), lo que es propio de la Teología o, si se quiere, del discurso del Religioso; tercero y último, optar por la filosofía, lo cual nos conduce «a admitir la posibilidad de realizar un día el idea de la Sabiduría» ${ }^{13}$ en «este» mundo (o sea, al margen de toda experiencia privilegiada que implique el acceso, más allá de la razón, a una forma cualquiera de trascendencia). Una vez entendida esta enumeración, la concepción hegeliana resulta en este punto muy clara: en el Saber teológico el sujeto cognoscente y el objeto conocido permanecen el uno fuera del otro (porque ese sujeto es inmanente, en tanto que su objeto es trascendente), en tanto que en el Saber del filósofo convertido en Sabio ambos coinciden - porque el objeto de este segundo Saber es la

12 A. Kojeve, op. cit., p. 26.

13 Ibid., p. 27. 
Autoconciencia, que solo puede alcanzarse a través del inmenso rodeo por el que el sujeto accede al conocimiento de la totalidad de lo existente. Cabe decir, no obstante, que la religión conoce igualmente una unión de sujeto cognoscente y objeto conocido, a saber: la «unión mística» del hombre y de Dios. Ahora bien, la mística nada tiene que ver con la Religión (o, lo que es igual para Hegel, con la Teología), porque esa «unión mística» se realiza en silencio y excluye, por consiguiente, toda forma de conocimiento. No hay, así, Saber místico en el mismo sentido en el que hay Saber filosófico o Saber religioso (o teológico) - y por ello cuando el místico habla de su Dios «inefable», o bien enuncia un Saber teológico que no difiere del que acabamos de describir, o bien elabora una teología «heterodoxa», antropoteísta, que se aproxima más o menos al Saber filosófico al que Hegel alude en el Capítulo VIII de su Fenomenología del espiritu. El supuesto Saber del místico lleva a éste, en suma, o bien a callar, o bien a contradecirse existencialmente (ya que al hablar transita invariablemente por una de las dos vías citadas - la religiosa y la filosófica -, a las que previamente se había negado). Por el contrario, tanto el Saber del religioso como el del filósofo remiten al uso del lenguaje; pero, si el primero podría prolongar su discurso indefinidamente (porque su objeto es un Ser que, en tanto que transcendente, necesariamente se le escapa), en cambio el segundo (por el carácter circular y, consiguientemente, finito de su Saber) podría, tras decir la verdad completa, sumirse en el silencio para siempre. Comprobamos entonces que para Hegel el lenguaje del filósofo es, de nuevo, un medio cuyo fin no es otro que la transmisión del Saber, por lo que no posee espesor alguno. Y, a pesar de ello, es a este mismo lenguaje (esto es, a la «prosa filosófica») al que Hegel considera, en sus Lecciones sobre la estética, superior a la poesía (Dichtung), es decir, a la literatura en general. Es a dicho lenguaje, al que cabe denominar «reflexivo» - porque, partiendo del sujeto pensante, tiene por objeto retornar a este último tras el enorme rodeo que supone el conocimiento del mundo, alcanzando así dicho sujeto la Autoconciencia -, al que corresponde, pues, no solamente un privilegio frente a todo otro tipo de lenguaje filosófico, sino también ante toda producción literaria, dado el carácter lingüístico de esta última.

En contraste con lo que acabamos de exponer, el lenguaje implicado en la inversión del hegelianismo no podrá ser el medio reflexivo para la adquisición de un Saber que, tras su consecución y su completa transmisión por recurso a este mismo lenguaje, podría ser abandonado - sino, al contrario, un «lenguaje del afuera» al que Foucault consagró un artículo homónimo, centrado esta vez en la aportación de Blanchot. Si este lenguaje del afuera (el propio de la literatura contemporánea y, por consiguiente, aquel al que antes asociamos la noción de «simulacro») puede ser descrito como pura exterioridad desplegada (para así oponerlo a la circularidad reflexiva del lenguaje a la que aludimos en 
el párrafo inmediatamente anterior), es porque no cabe limitarlo ni por medio del discurso (es decir, por la consistencia interior del lenguaje que se ciñe a los principios de la razón) ni por la transmisión de un sentido (lo que nos reenviaría al modelo de Lasswell). Si la literatura se ha vuelto autoreferencial durante el siglo XX no es, así, para reproducir el carácter reflexivo del discurso sino, al contrario, para escapar al lenguaje reflexivo, manifestándose desde entonces como un lenguaje puesto «fuera de sí» y desvelando, en ese mismo trance, su ser propio, que tiene más que ver con una distancia que con un repliegue, más con una dispersión que con un retorno. Así, pues, mientras el «pensamiento del pensamiento» (es decir, la reflexión) conducía a la interioridad más profunda (para culminar, con Hegel, nada menos que en la pretensión de una Autoconciencia absoluta), la «palabra de la palabra» (o sea, el lenguaje estrictamente literario) remite, por el contrario, a un afuera en el que el sujeto desaparece, por irrelevante para lo que en dicha palabra se pone en juego. Este es acaso el motivo, especula Foucault, por el que ese «pensamiento del afuera» ha sido largamente conjurado, expulsado de la cultura occidental, que únicamente lo esboza en sus márgenes - o sea, de entrada, en el monólogo reiterativo de Sade (que pone al desnudo el deseo en el murmullo infinito del discurso) y en la poesía de Hölderlin (en la que se enuncia la ausencia de los dioses y «la obligación de aguardar, sin duda hasta el infinito, la ayuda enigmática que procede de la 'ausencia de Dios' $\gg{ }^{14}$ ). Pero esta experiencia del afuera, formulada durante la primera mitad del XIX por estas dos vías (el deseo y la ausencia de Dios) no hubiera llegado hasta nosotros de no haber sido verbalizada más tarde por Nietzsche, Mallarmé, Artaud, Bataille y Klossowski, hasta llegar finalmente a Blanchot - que no es, según Foucault, un testigo más de esa experiencia, sino «la presencia real, absolutamente lejana, resplandeciente, invisible, la suerte necesaria, la ley inevitable, el vigor calmado, infinito, mesurado de ese pensamiento» ${ }^{15}$.

\section{LA INVERSIÓN DEL SCHOPENHAUERIANISMO (I): LA METAFÍSICA}

Como hemos anticipado, el privilegio concedido por el hegelianismo al lenguaje reflexivo implica la primacía de este último sobre la literatura (porque solo la prosa filosófica es, según Hegel, un medio idóneo para decir la verdad última de la literatura, de cuyo lenguaje se distinguiría aquélla por principio). Esta prioridad de la reflexión sobre la literatura no se habría manifestado desde siempre, sino solo en la fase suprema de la modernidad (y, por lo tanto, de la Historia), es decir, en aquel momento en el que "el arte va más allá de sí mismo al abandonar el elemento de la sensibilidad reconciliada del espíritu y

14 M. Foucault, Entre filosofia y literatura. Obras esenciales, Volumen I, op. cit., p. 300.

15 Ibid., 301-302. 
pasar de la poesía de la representación [Vorstellung] a la prosa del pensar"16. Por el contrario, el lenguaje que conviene al pensamiento del afuera (y que, en la medida en que no reconduce ese pensamiento a la dimensión de la interioridad, no puede hacer un uso dialéctico de la negación) no tiene que ver con la Historia ni, por consiguiente, con el tiempo, sino más bien con el espacio - ahora entendido no como un sistema cerrado (esto es, como una suerte de marco inmóvil en el que sería posible delimitar compartimentos fijos), sino como una progresión incesante en la que ninguna frontera es estable y donde, por consiguiente, «la distinción entre 'novelas', 'relatos' y 'crítica' no deja de atenuarse ${ }^{17}$.

Para determinar en qué sentido esta última deriva termina por desembocar en una inversión del schopenhauerianismo debemos, antes que nada, aclarar qué entenderemos en lo sucesivo por «el pensamiento de Schopenhauer»para lo que asumiremos, a su vez, como punto de partida la siguiente tesis: a diferencia de Kant, que denominó «fenómeno» a todo cuanto podemos conocer, y «noúmeno» (o «cosa en sí»)) al límite negativo de ese conocimiento, Schopenhauer consideró en cambio el fenómeno (o, lo que es igual para él, la «representación») como aquello que no es, salvo como ilusión o engaño, y el noúmeno (o la «voluntad») como la realidad verdadera. De este modo, Schopenhauer adhirió a lo que había sido una mera distinción epistemológica (entre lo cognoscible y lo no cognoscible) un juicio de carácter ontológico (por el que se pasa a hablar de algo así como la «falsa apariencia» frente al «verdadero ser») en virtud del cual uno de los dos términos aludidos (la voluntad) pasó a ser considerado más «real» que el otro. Esta prevalencia de la voluntad frente a la representación es también, para este filósofo, la de lo irracional sobre lo racional, y ello por lo que sigue: siempre que indagamos la razón de algo buscamos el «por qué» de ese «algo», pero cuando hallamos esta razón podemos a su vez preguntarnos por el «por qué» de la misma, y así indefinidamente; ahora bien, ese proceso de indagación racional, que nos remite en cada caso de la consecuencia a la razón o del efecto a la causa, o bien no tiene un punto final (y entonces la serie entera de los fenómenos interrogados carece de razón o, también, de sentido último), o bien sí que lo tiene - en cuyo caso, o ese término final da razón de sí mismo (ya por principio y desde siempre, como sucede en Spinoza, ya por recurso al largo rodeo de la Historia, como en Hegel), o es un irracional puro (con lo que, paradójicamente, la serie entera de los fenómenos racionales se sustenta sobre el sinsentido absoluto). La última de estas opciones es la de Schopenhauer, y

16 G. W. F. Hegel, Lecciones sobre la estética, trad. de A. Brotons Muñoz, Madrid: Akal, 2007, p. 66.

17 M. Foucault, Entre filosofía y literatura. Obras esenciales, Volumen I, op. cit., p. 304. 
su asunción lleva a este pensador a considerar que, si bien las representaciones son relativas (porque remiten necesariamente a otra instancia más «verdadera» que ellas) y están siempre sometidas a las leyes de la razón y de la causalidad, en cambio la voluntad es un absoluto (pues no nos reenvía a instancia ulterior alguna) irracional y, por lo tanto, libre (porque no se halla sometida a las leyes causales y racionales). Además, y dado que lo absoluto o lo incondicionado es uno y lo mismo para todo (lo que para Schopenhauer quiere decir que todo es igualmente irracional, por más que no todo lo parezca a primera vista), habrá que concluir que la voluntad es solo una, y que la multiplicidad de las representaciones no es más que una inmensa sucesión de falseamientos de ese fondo irracional. Más todavía: como el sinsentido absoluto no se ve alterado por las modificaciones que en el orden fenoménico introducen las series causales y racionales, resultará que, por contraste con el carácter temporal de las representaciones, la voluntad es atemporal o, lo que es igual, eterna.

Los tres rasgos que, según acabamos de ver, Schopenhauer atribuye a la voluntad (es decir, la unidad, la eternidad y la libertad) constituyen el objeto de la primera gran crítica que Nietzsche arrojó contra la filosofía de ese pensador. Intentaremos mostrar el modus operandi de dicha crítica observando lo que sigue a propósito del primero de esos tres rasgos: por haber contrapuesto la voluntad a la «representación» (en el mismo sentido en que la «cosa en sí» o el noúmeno se opone al fenómeno), Schopenhauer no pudo entender la voluntad más que en términos de «unidad», esto es, por oposición a la multiplicidad de las representaciones; ahora bien, al igual que las representaciones no son múltiples sin conformar «una» multiplicidad, la voluntad tampoco puede ser una sin constituirse en algún sentido, y simultáneamente, como múltiple. Si se asume que este tipo de circunstancias pueden no tener nada que ver con una condición de lo real, sino solo con una forma inherente a nuestra manera de captar lo real (o sea, a «nuestra organización»), entonces habrá que concluir que

Para los tres predicados de unidad, eternidad (o sea, atemporalidad) y libertad (o sea, la no causalidad) vale lo mismo que para la cosa en sí: están, sin excepción, indisolublemente ligados a nuestra organización, de modo que es sumamente dudoso que puedan tener la menor importancia fuera de la esfera del conocimiento. Sin embargo, ni Kant ni Schopenhauer nos demuestran ni logran hacer verosímil a nuestros ojos que estos predicados deban ser los atributos de la cosa en sí por el hecho de que los atributos contrarios sean dominantes en el mundo fenoménico. Schopenhauer no podría hacerlo por el hecho de que su cosa en sí, la voluntad, no puede bastarse a sí misma con sus tres predicados, sino que 
está siempre obligada a tomar en préstamo algo del mundo fenoménico, o sea, a aplicarse a sí misma las nociones de multiplicidad, temporalidad y causalidad. ${ }^{18}$

Si, como hemos sostenido, la crítica que Nietzsche dirigió a la metafísica schopenhaueriana se prolonga en la concepción foucaultiana de la literatura, entonces habrá de ser posible encontrar en esta última el resultado de la inversión de los tres rasgos en virtud de los que esa metafísica caracterizó a la voluntad, que es su principal noción. Como reservaremos lo relativo a la inversión de la eternidad o de la atemporalidad ligada a ese espacio literario para la siguiente (y última) sección de nuestro escrito, que es la propiamente estética, nos centraremos por el momento en la inversión por parte de la literatura moderna del tercero de los rasgos que Schopenhauer vinculó a la voluntad (esto es, la libertad o, lo que es equivalente en la terminología de este autor, la no causalidad). Es a este respecto que Foucault advierte que en Raymond Roussel el proceso de escritura parte de una frase escogida al azar para, a continuación, someter dicha frase a un procedimiento - o sea, a un conjunto de reglas de sustitución, de asociación y de combinación que, considerado en sí mismo, es absurdo, pero que sirve este escritor para desvincular a la literatura de los prestigios de la imaginación y, en general, de todas las peculiaridades psicológicas con las que (al menos, desde el romanticismo) se revistió al genio. Arbitrario en lo que a la frase de partida se refiere y mecánico en la aplicación del procedimiento a esa misma frase, lo que no hay en el lenguaje literario de Roussel (y lo que, por consiguiente, puede ser desterrado de la esencia del lenguaje literario en general) es la exigencia de una «inspiración» o de una «libre fantasía» por parte del escritor - cuya única libertad consistirá, en todo caso, en la determinación de las reglas del procedimiento, a las que deberá someterse en lo sucesivo para «organizar, según el discurso menos aleatorio, el más inevitable de los azares» ${ }^{19}$.

\section{LA INVERSIÓN DEL SCHOPENAHUERIANISMO (II): LA ESTÉTICA}

En el párrafo inmediatamente anterior hemos dicho que reservaríamos el problema de la inversión de la eternidad (o de la atemporalidad) de la voluntad para el momento en el que introdujéramos una consideración sobre la estética de Schopenhauer. Los rudimentos de esta estética se exponen, como es sabido, en la tercera sección del volumen primero de El mundo como voluntad y representación, ubicación que responde al siguiente doble criterio: en primer lugar, para Schopenhauer (como, antes que él, para Kant) en toda intervención

18 P I 6, Otoño de 1867 - Primavera de 1868, 57 [55], en F. Nietzsche, Obras completas. Volumen I., trad. de J. B. Llinares, D. Sánchez Meca y L. E. de Santiago Guervós, Madrid: Tecnos, 2011, p. 297.

19 M. Foucault, Raymond Roussel, trad. de P. Canto, Buenos Aires: Siglo XXI, 1999, p. 53. 
de nuestras facultades subjetivas cabe identificar dos usos distintos, uno superior y otro inferior; y, segundo, podemos experimentar el mundo tanto desde la perspectiva de la representación como desde la de la voluntad. Combinando estos dos criterios se obtienen los siguientes cuatro resultados, que Schopenhauer ordena de menor a mayor relevancia ontológica: en primer lugar, el nivel inferior de la representación; a continuación, el nivel inferior de la voluntad; en tercer lugar, el nivel superior de la representación; y, finalmente, el nivel superior de la voluntad. Pues bien, como el arte le parece a Schopenhauer la forma superior de la representación, este autor entiende que, dentro de la jerarquía que acabamos de citar, el lugar idóneo para el tratamiento de los problemas artísticos es la tercera sección, significativamente titulada «Segunda consideración del mundo como representación. La representación, independientemente del principio de razón. La idea platónica. El objeto del arte».

Resumiremos la tesis fundamental de la estética que en esta sección se formula, y que tanto influyera en el joven Nietzsche, señalando únicamente lo que sigue: la vida es esencialmente dolorosa (ya que está fundada sobre el absurdo de la existencia, al que Schopenhauer llamó «voluntad»), pero el arte (a diferencia de la ciencia y de la acción práctica, que conforman respectivamente los niveles inferiores de la representación y de la voluntad) no nos incita a intervenir sobre los objetos con los que nos relaciona (es decir, sobre las obras de arte), sino solo a contemplarlas. Schopenhauer considera que, por esta vía, la obra de arte nos invita a apartarnos del dolor que conlleva necesariamente la vida, ofreciéndonos un consuelo que proviene del hecho de que, al contemplar esa obra, entramos en relación con la idea que el artista ha querido transmitirnos a través de aquélla. Resulta, sin embargo, muy evidente que las ideas a las que se refiere Schopenhauer en este punto nada tienen que ver con la Idea hegeliana - la cual, por desplegarse históricamente, se encuentra ligada a su realización en el espacio y, sobre todo, en el tiempo -, sino las con ideas platónicas - que se caracterizan, en cambio, por hallarse más allá del tiempo y del espacio. Por todo ello, Schopenhauer considera que

El arte reproduce las ideas eternas capturadas a través de la contemplación pura, lo esencial y lo permanente de todos los fenómenos del mundo y, según el material con el que los reproduzca, será arte plástico, poesía o música. Su único origen es el conocimiento de las ideas; su única meta la comunicación de ese conocimiento. ${ }^{20}$

20 A. Schopenhauer, El mundo como voluntad y representación, Vol. I, trad. de R. Aramayo, Barcelona: Círculo de Lectores, 2004, p. 275. 
Así, pues, a través de la contemplación a la que nos invita, la obra de arte «para la rueda del tiempo» ${ }^{21}$ e intenta sacarnos - a nosotros, sus espectadores de esa rueda, si bien dicha «salida fuera del tiempo» no puede tener lugar más que por un tiempo, lo que constituye la primera gran paradoja de la estética schopenhaueriana. La segunda de tales paradojas afecta, por su parte, no ya a la naturaleza de la obra de arte, sino a su producción - y, en consecuencia, a la figura del artista del artista verdaderamente digno de ese nombre (o sea, al genio). Dicho artista es para Schopenhauer el individuo que, tras haber contemplado la idea cuyo conocimiento desea hacernos llegar, se decide a actuar para crear una obra de arte que, en efecto, nos la transmita. En esto se manifiesta un nuevo rasgo platónico en Schopenhauer, ya que el genio así descrito recuerda vivamente al anónimo protagonista del «mito de la caverna» de Platón, que debe renunciar - temporalmente, se entiende - a prolongar indefinidamente su contemplación de lo que encuentra en el exterior de la caverna para hacer partícipes de dicha visión a otros congéneres suyos.

Lo expuesto sobre las dos paradojas fundamentales de la estética schopenhaueriana debería bastarnos para entender que ésta es, en términos generales, solidaria no solamente de algunos elementos de lo que hemos llamado «platonismo», sino también del modelo de Lasswell al que nos referimos al inicio de estas páginas. Pero si, al hablar de la primera de esas paradojas, hemos reproducido unas líneas en las que Schopenhauer hacía depender la distinción entre el arte plástico, la poesía y la música del material utilizado en cada una de estas artes, es para observar a continuación que la jerarquía que, según este autor, acompaña a dicha distinción obedece a un criterio (de nuevo) doble. En efecto, Schopenhauer considera, de una parte, que puesto que las obras de arte intentan expresar por recurso a elementos materiales (y, por consiguiente, espaciotemporales) las ideas platónicas, que son en principio ajenas tanto al espacio como al tiempo, habrá que considerar superiores (como ya dijera Hegel) a aquellas artes que requieran una menor cantidad de materia para plasmar la idea; pero, además, dentro de cada una de esas artes, el autor de Parerga y Paralipómena piensa que debemos juzgar superiores a las manifestaciones artísticas en que se representa la victoria de la contemplación sobre el tiempo - y, por lo tanto, de lo irracional sobre el concepto. Como consecuencia de la aplicación de este nuevo doble criterio entenderá Schopenhauer que en la cima de la jerarquía de las artes debe situarse una disciplina artística particularmente ajena a la razón - entendida esta última como la capacidad de sistematizar las representaciones y, en consecuencia, como aquello que tiende por principio a alejarnos de la voluntad -, siendo ésta no ya la poesía (contra lo sostenido, por motivos diversos, tanto por Kant

21 Ibid., p. 276. 
como por Schelling y Hegel), sino la música - y, de entre todas las formas de música, especialmente aquella que, por consistir en un flujo armónico desligado no solo de toda palabra, sino también de toda pauta armónica, incita en mayor medida a la contemplación y, por lo tanto, a dar la espalda al mundano ajetreo ${ }^{22}$.

La superioridad de la música sobre la poesía (entendida, una vez más, como Dichtung, esto es, como arte literario en general) se establece en $E l$ mundo como voluntad y representación a partir de un criterio que relaciona el carácter ilusorio de las representaciones racionales con la valoración negativa que tanto el tiempo como el espacio merecen a Schopenahuer. Es en este punto donde el Nietzsche de, por ejemplo, El nacimiento de la tragedia coincide todavía con Schopenhauer, de quien en cambio Foucault parece discrepar radicalmente. Se diría, en efecto, que si para el autor de Las palabras y las cosas debe rechazarse todo nexo esencial entre la literatura y el tiempo (para invertir el hegelianismo), no debe en cambio negarse el vínculo de ésta con el espacio (ya que, de lo contrario, se recae en el platonismo, como visiblemente le ocurrió a Schopenhauer al hablar del arte, y no se culmina el proyecto nietzscheano). Y, no obstante, en un artículo publicado por primera vez en 1963 y titulado «Distance, aspect, origine» observa Foucault que, aunque el lenguaje de la ficción «se inserta en el lenguaje ya dicho, en un murmullo que nunca ha comenzado» ${ }^{23}$, ese lenguaje tiene por origen la escritura como acto, que solo existe en presente - esto es, en un tiempo por debajo del tiempo y del espacio, del mismo modo que la «distancia» a la que alude el título que acabamos de citar es un espacio en un sentido muy particular, y al que ya nos hemos referido. Foucault parece, entonces, entrever la posibilidad de sortear el escollo del hegelianismo sin necesidad de renunciar con ello a establecer algún tipo de relación entre la literatura y el tiempo - pero a condición de entender al tiempo no ya en términos histórico-cronológico, sino como puro presente del que brotan dos flujos simultáneos (uno que continuamente amplía y reinterpreta el pasado, de una parte, y otro que avanza permanentemente hacia el futuro, de otra) y que resultaría compatible con la doblez que hemos ligado a la esencia misma del lenguaje literario.

En suma, cifraremos lo esencial del «schopenhauerianismo» que, a nuestro juicio, se trata de invertir en la concepción foucaultiana de la literatura en los cuatro puntos que siguen: primero, en la obra literaria se trata (como, en

22 En sus primeros escritos, Friedrich Nietzsche ensalzó la música en términos muy similares a los utilizados por Schopenhauer, precisamente por la influencia de éste. Posteriormente se fue distanciando, sin embargo, de los planteamientos schopenhauerianos, entendemos que sobre todo por cuanto, como hemos dicho, le pareció que hablar de una voluntad única implicaba suprimir las diferencias entre las voluntades particulares.

23 M. Foucault, Entre filosofía y literatura. Obras esenciales, Volumen I, op. cit., p. 258. 
general, en toda obra artística) de plasmar ciertas Ideas platónicas (prioridad del Mensaje, o versión trascendente del esquema de Lasswell todavía presente en Schopenhauer); segundo, si el arte recurre a la materia (es decir, a lo espacio-temporal) para plasmar las Ideas, hay que entender que este elemento material no es otra cosa que un mal necesario y, por ello mismo, que cuanto menos materia precise la obra de arte para manifestar la Idea (esto es, cuanto más ajena sea aquélla tanto al espacio como al tiempo), tanto más elevada será esa obra (platonismo inherente la estética schopenhaueriana); en tercer lugar, dado que la Idea no se confunde con el concepto (porque éste es el universal que nuestra razón construye mediante un proceso en el que se abstraen determinados elementos de la realidad espacio-temporal, en tanto que aquélla es el universal lógicamente anterior al espacio y al tiempo), y como la literatura se maneja con palabras, o sea, con un lenguaje conceptual (elemento hegeliano aún reconocible en Schopenhauer), habrá que concluir que cierto tipo de música es por principio superior a cualquier otra manifestación artística y, por extensión, literaria; cuarto y último, más allá incluso de las Ideas, lo que se trata de manifestar finalmente en el arte es el fondo último de lo real, esto es: la voluntad única de la que emana toda representación (elemento que Schopenhauer tomó del hinduismo y que constituye, acaso, su principal aportación no solo a la filosofía, sino a la cultura occidental en su totalidad). Por contraste con esos cuatro puntos cabe decir, ante todo, que para Foucault el lenguaje literario no tiene otro asunto que su propia doblez, de manera que resulta irreductible a la condición de simple medio para la transmisión de un mensaje, por más trascendente que éste sea (inversión del modelo de Laswell); a continuación, que si bien la literatura no remite a materia alguna, no puede decirse que sea absolutamente ajena al espacio y al tiempo, ya que es indisociable de un espacio propiamente literario - $y$, tal vez, también a un tiempo no histórico, como hemos expuesto -, de modo que no tiene sentido decir que en ella se halla en juego la "verdadera» realidad, que se opondría a la «falsa» apariencia como el Bien al Mal (inversión del platonismo); tercero, que la palabra literaria no es conceptual, por lo que eso que en ella es puesto en juego no es en modo alguno una abstracción de la que el lenguaje reflexivo daría cuenta más adecuadamente que la propia literatura (inversión del hegelianismo); cuarto y último, que no es la voluntad única, sino la multiplicidad de las potencias que englobamos en el término «voluntad» aquello que el lenguaje literario tiene como tarea manifestar, de donde se sigue que el suyo es un espacio de la dispersión, de la multiplicidad irreductible al principio de la unidad, a la vez que independiente de toda presunción de libertad de la fantasía y - según hemos dicho - de toda presunción de eternidad (inversión del schopenhauerianismo, tanto metafísico como estético). En este cuarto y último punto es donde nos parece que Foucault prolonga de una 
manera más evidente a Nietzsche; pero, dado que para Schopenhauer todos los aspectos que hemos enumerado son indisociables, tendremos que considerar la posibilidad de que el ascendente nietzscheano impregne las cuatro inversiones citadas - en cuyo caso, tal vez sean éstas los puntos cardinales por medio de los cuales sería posible orientarse en la intrincada masa de textos en la que Foucault plasmó su concepción de la literatura. 
